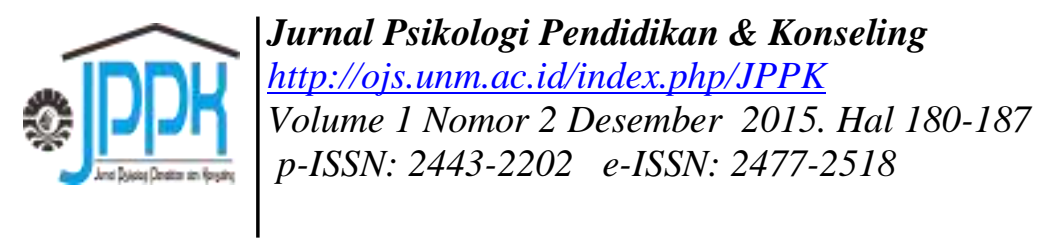

\title{
EVALUASI PROGRAM KONSELING DI SMP KOTA MALANG: DISCREPANCY MODEL
}

\author{
Wahyu Nanda Eka Saputra \\ Prodi Bimbingan dan Konseling Fakultas Keguruan dan Ilmu Pendidikan \\ Universitas Ahmad Dahlan \\ Email: wahyu.kons@gmail.com
}

\begin{abstract}
This study aims to determine the discrepancy between the performance of counseling program of Junior High School in Malang with standards. This study uses a standard of Guidelines for Performance Based Professional School Counselor Evaluation. Standard reads, "the professional school counselor counsels individual students and small groups of students with identified needs/concerns". This study is an evaluation research. Evaluations were performed in this study using a discrepancy model. The approach used is a systems approach that is focused on the planning, implementation, and evaluation of counseling programs. Based on the analysis of the results of the evaluation, counseling programs in Junior Hight School in Malang is still far from standard. The results of this study recommend to counselors to improve the quality of the counseling program, so give a positive impact on students.
\end{abstract}

Keyword: program evaluation, counseling, discrepancy model

\begin{abstract}
Abstrak: Penelitian ini bertujuan untuk mengetahui kesenjangan antara performansi program konseling di SMP Kota Malang dengan standar yang telah ditentukan. Penelitian ini menggunakan standar dari Guidelines for Performance Based Professional School Counselor Evaluation. Standar tersebut berbunyi "konselor sekolah professional melaksanakan konseling pada siswa secara individual dan kelompok yang teridentifikasi kebutuhan dan masalahnya dan memerlukan bantuan". Penelitian ini adalah penelitian evaluasi. Evaluasi yang dilakukan dalam penelitian ini menggunakan discrepancy model. Pendekatan yang digunakan adalah pendekatan sistem yang difokuskan pada perencanaan, pelaksanaan, dan evaluasi program konseling. Berdasarkan analisis hasil evaluasi, program konseling di SMP Kota Malang masih jauh dari standar. Hasil penelitian ini merekomendasikan kepada konselor untuk memperbaiki kualitas pelaksanaan program konseling, sehingga memberikan pengaruh positif bagi siswa.
\end{abstract}

Kata kunci: evaluasi program, konseling, discrepancy model 


\section{PENDAHULUAN}

Program bimbingan dan konseling menggunakan pola bimbingan dan konseling komprehensif yang dirancang dalam empat bidang, yaitu layanan dasar, perencanaan individual, layanan responsif dan dukungan sistem (Gysbers \& Henderson, 2006; Gysbers, 2008; Gysbers dkk., 2008). Layanan dasar diartikan sebagai proses pemberian bantuan kepada semua peserta didik melalui kegiatankegiatan secara klasikal atau kelompok dengan disajikan secara sistematis dalam rangka membantu perkembangan dirinya secara optimal (Yusuf \& Nurihsan, 2009). Bentuk-bentuk layanan ini adalah bimbingan kelas, layanan orientasi, layanan informasi, bimbingan kelompok, dan layanan pengumpulan data. Layanan responsif adalah pemberian bantuan kepada peserta didik yang memiliki kebutuhan dan masalah yang memerlukan pertolongan dengan segera (Yusuf \& Nurihsan, 2009). Bentuk-bentuk layanan ini adalah layanan konseling, referal, kolaborasi dengan guru mata pelajaran atau wali kelas, kolaborasi dengan orang tua, kolaborasi dengan pihak-pihak terkait di luar sekolah, konsultasi, bimbingan teman sebaya, konferensi kasus, dan kunjungan rumah. Layanan perencanaan individual adalah proses bantuan kepada peserta didik agar mampu merumuskan dan melakukan aktivitas yang berkaitan dengan perencanaan masa depannya berdasarkan kekurangan dan kelebihan yang dimilikinya (Yusuf \& Nurihsan, 2009). Sedangkan dukungan sistem merupakan komponen layanan dan kegiatan manajemen yang secara tidak langsung memberikan bantuan kepada peserta didik untuk kelancaran perkembangan peserta didik (Yusuf \& Nurihsan, 2009).

Gibson \& Mitchell (2011) menyatakan bahwa jantung hati bimbingan dan konseling adalah program konseling. Beberapa hasil penelitian telah menunjukkan bahwa program konseling memiliki pengaruh yang signifikan dalam mengubah tingkah laku konseli. Penelitian yang dilaksanakan oleh Spilsbury (2012) menyimpulkan bahwa Konseling Ringkas Berfokus Solusi dapat menurunkan depresi dan ketergantungan alkohol. Penelitian yang dilaksanakan Scheeringa dkk. (2007) menunjukkan bahwa penerapan konseling dengan cognitive-behavior therapy dapat menurunkan posttraumatic stress disorder (PTSD). Penelitian González-Prendes \& Jozefowicz-Simbeni (2009) menunjukkan bahwa Cognitive-Behavior Therapy dapat menurunkan marah dan paranoid ideation. Penelitian yang dilaksanakan oleh Olubusayo (2014) menunjukkan bahwa penerapan teknik cognitive restructuring dapat menurunkan kecemasan siswa SMA pada mata pelajaran matematika.

Sedangkan beberapa hasil penelitian yang telah dilaksanakan di Indonesia juga menunjukkan bahwa program konseling memiliki pengaruh yang signifikan dalam mengubah tingkah laku konseli. Penelitian yang dilaksanakan oleh Saputra (2011) menunjukkan bahwa penerapan konseling kelompok Gestalt dapat meningkatkan rasa percaya diri siswa SMA. Penelitian yang dilakukan Saputra (2015) menyimpulkan bahwa penerapan konseling dengan teknik cognitive restructuring dapat menurunkan prokrastinasi akademik siswa SMK.

Pemaparan hasil-hasil penelitian di atas menunjukkan bahwa program konseling menjadi tumpuan dalam layanan bimbingan dan konseling di sekolah. Fungsi program konseling adalah membantu konseli menyadari kekuatan konseli, menemukan yang menghalangi kekuatan itu, dan memperjelas konseli ingin menjadi pribadi yang bagaimana (Corey, 2009). Akan tetapi, program konseling belum menjadi perhatian serius konselor sekolah. Hal tersebut dapat menurunkan efektifitas program konseling yang dilaksanakan konselor sekolah.

Terdapat beberapa penelitian yang menunjukkan konselor sekolah belum bisa melaksanakan program konseling yang efeftif. Penelitian Juntika 1993 (dalam Akhmadi, 2012) menyimpulkan masih kurangnya kemampuan konselor dalam menangani dan menggali masalah yang dihadapi siswa. Penelitian Marjohan 1994 (dalam Akhmadi, 2012) juga menemukan 39,47\% konselor dapat menerapkan kemampuan profesional konseling dalam kategori tinggi, sedangkan $60,53 \%$ hanya mampu menerapkan kemampuan tersebut pada kategori sedang.

Program konseling adalah jatung hari program bimbingan dan konseling (Gibson \& Mitchell, 2011). Program konseling perlu dilaksanakan evaluasi. Hasil evaluasi yang dilaksanakan akan digunakan sebagai dasar 
untuk memverifikasi kekuatan dan kelemahan program konseling (Otto, 2001).

Salah satu model evaluasi yang bisa digunakan untuk mengevaluasi program konseling adalah evaluasi discrepancy model. Model evaluasi ini dikembangkan oleh Malcom Provus yang bertujuan untuk mengetahui tingkat kesesuaian antara standar yang telah ditentukan dengan penampilan aktual dari pelaksanaan program konseling (Fitzpatrick, Sanders \& Worthen, 2004; McKenna, 1981). Provus (dalam Fitzpatrick, Sanders \& Worthen, 2004) memandang evaluasi ini sebagai proses yang mencakup (a) kesepakatan tentang standar tertentu; (b) menentukan ada/tidak ada kesenjangan yang muncul antara performansi dan aspek program dengan perangkat standar tertentu; dan (c) menggunakan informasi tersebut sebagai dasar membuat keputusan untuk mengembangkan, melanjutkan, atau menghentikan program tersebut.

Standar dan kriteria program konseling dirujuk dari Guidelines for Performance Based Professional School Counselor Evaluation (Missouri Department of Elementary and Secondary Education, 2000). Standar evaluasi program konseling berada pada standar 3 kriteria 5 yang berbunyi "konselor sekolah professional mengkonseling siswa secara individual dan kelompok yang teridentifikasi kebutuhan dan masalahnya dan memerlukan bantuan." Program konseling individu, konselor perlu membuat sebuah program yang mencakup perencanaan, pelaksanaan, dan evaluasi program konseling individu (Winkel, 1991). Evaluasi program konseling ini dilaksanakan di SMP Kota Malang. Muara dari evaluasi program konseling ini adalah dirumuskannya rekomendasi mengenai keberlanjutan program konseling di masa mendatang.

Beberapa ahli mendefinisikan pengertian konseling. Konseling adalah upaya membantu individu melalui proses interaksi yang bersifat pribadi antara konselor dan konseli agar konseli mampu memahami diri dan lingkungannya, mampu membuat keputusan dan menentukan tujuan berdasarkan nilai yang diyakininya sehingga konseli merasa bahagia dan efektif perilakunya (Shertzer \& Stone, 1980). Definisi lain dari konseling adalah proses membantu individu untuk mengenal dirinya sendiri, mengenal lingkungan sekitarnya, dan cara-cara untuk mengatasi perputaran kehidupan dan hubungannya dengan orang lain (Hansen, Stevic \& Warner, 1977).

Evaluasi discrepancy model. Boulmetis \& Dutwin, 2000 (dalam Astramovich \& Coker, 2007) menyatakan bahwa evaluasi program adalah proses yang sistematis untuk mengumpulkan dan menganalisis informasi efisiensi, efektifitas, dan pengaruh program terhadap perubahan tingkah laku konseli, Model evaluasi ini dikembangkan oleh Malcom Provus yang bertujuan untuk mengetahui antara tingkat kesesuaian antara standar yang telah ditentukan dengan penampilan aktual dari pelaksanaan program konseling (Fitzpatrick, Sanders \& Worthen, 2004; McKenna, 1981). Provus (dalam Fitzpatrick, Sanders \& Worthen, 2004) memandang evaluasi ini sebagai proses yang mencakup (a) kesepakatan tentang standar tertentu; (b) menentukan ada/tidak ada kesenjangan yang muncul antara performansi dan aspek program dengan perangkat standar tertentu; dan (c) menggunakan informasi tersebut sebagai dasar membuat keputusan untuk mengembangkan, melanjutkan, atau menghentikan program tersebut.

\section{METODE PENELITIAN}

Penelitian ini adalah penelitian evaluasi. Evaluasi yang dilakukan dalam penelitian ini menggunakan discrepancy model yang membantu administrator membuat keputusan (Dimmitt, 2010). Pendekatan yang digunakan adalah pendekatan sistem yang difokuskan pada perencanaan, pelaksanaan, dan evaluasi program konseling di SMP Kota Malang.

Discrepancy model merupakan model evaluasi yang dikembangkan oleh Malcom Provus. Provus mendefinisikan evaluasi sebagai proses dari (1) menentukan standar program; (2) menentukan perbedaan antara kinerja dengan standar; (3) menggunakan ketidaksesuaian sebagai bahan untuk mengubah kinserja atau standar program (Fitzpatrick, Sanders \& Worthen, 2004). Panduan untuk mengevaluasi program konseling individu menggunakan standar evaluasi program dari Guidelines for Performance Based Professional School Counselor Evaluation (Missouri Department of Elementary and Secondary Education, 2000).

Tujuan dari pelaksanaan evaluasi program konseling ini adalah untuk mengetahui 
kesenjangan antara performansi program konseling di SMP Kota Malang dengan standar yang telah ditentukan.

\section{HASIL DAN PEMBAHASAN}

\section{Hasil}

Menurut panduan evaluasi program bimbingan konseling dari Guidelines for Performance Based Professional School Counselor Evaluation (Missouri Department of Elementary and Secondary Education, 2000), standar evaluasi program konseling berada pada standar 3 kriteria 5 yang berbunyi "konselor sekolah professional melaksanakan konseling pada siswa secara individual dan kelompok yang teridentifikasi kebutuhan dan masalahnya dan memerlukan bantuan." Kriteria tersebut dijabarkan dalam bentuk kriteria penilaian untuk menentukan program konseling sesuai dengan standar, mendekati standar, atau jauh dari standar. Adapun rubrik penilaian secara rinci dapat dijelaskan pada tabel di bawah ini.

Tabel 1. Rubrik Penilaian

\begin{tabular}{|c|c|c|}
\hline No & Kriteria & Keterangan \\
\hline 1 & $\begin{array}{l}\text { Terlaksana } \\
100 \%\end{array}$ & $\begin{array}{l}\text { Sesuai dengan } \\
\text { standar }\end{array}$ \\
\hline 2 & $\begin{array}{l}\text { Terlaksana } \\
77 \%\end{array}$ & Mendekati standar \\
\hline 3 & Terlaksana $\leq 65 \%$ & Jauh dari standar \\
\hline
\end{tabular}

Setelah menentukan rubrik penilaian, evaluator melaksanakan analisis hasil evaluasi program konseling. Instrumen utama yang digunakan dalam penelitian ini berupa kuesioner evaluasi program konseling. Berdasarkan hasil analisis data kuesioner evaluasi program konseling, SMP Kota Malang masih jauh dari standar. Hal ini dikarenakan di SMP tersebut hanya 51,1\% aspek kegiatan program konseling telah terlaksana dengan baik. Selanjutnya, di SMP tersebut setidaknya terdapat $17,8 \%$ aspek kegiatan program konseling yang hanya terlaksana sebagaian. Sedangkan untuk program konseling yang tidak terlaksana sama sekali di SMP tersebut adalah $31,1 \%$.
Adapun data tersebut dapat digambarkan secara rinci dalam bagan di bawah ini.

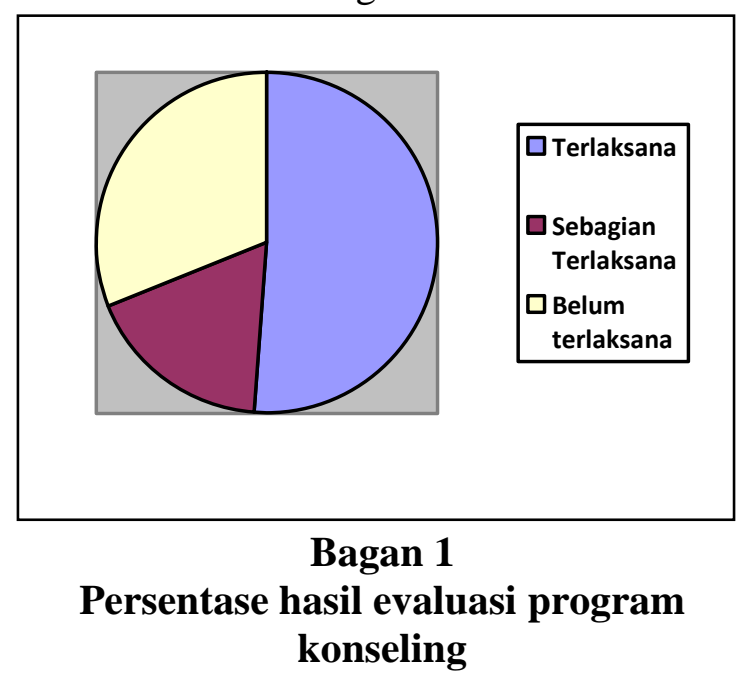

\section{Pembahasan}

Telah disebutkan dalam pemaparan di atas bahwa evaluasi yang dilaksanakan menggunakan evaluasi discrepancy model. Evaluasi discrepancy model memberikan gambaran kesenjangan yang terjadi antara performansi program konseling dengan standar yang telah ditentukan. Menurut panduan evaluasi program bimbingan konseling dari Guidelines for Performance Based Professional School Counselor Evaluation (Missouri Department of Elementary and Secondary Education, 2000), standar evaluasi program konseling berada pada standar 3 kriteria 5 yang berbunyi "konselor sekolah professional mengkonseling siswa secara individual dan kelompok yang teridentifikasi kebutuhan dan masalahnya dan memerlukan bantuan." Berdasarkan hasil analisis kuesioner evaluasi program konseling dapat dipahami bahwa program konseling di SMP Kota Malang masih jauh dari standar. Kuesioner evaluasi program konseling tersebut juga diperkuat dengan adanya instrumen lain, yaitu pedoman wawancara evaluasi program konseling, dan studi dokumentasi.

Berdasarkan hasil kajian secara komprehensif kuesioner evaluasi program konseling, pedoman wawancara evaluasi program konseling, dan studi dokumentasi, terdapat beberapa kegiatan yang tidak bisa dilaksanakan konselor dengan baik. Beberapa kagiatan yang belum dilaksanakan konselor dengan baik adalah: 
(a) Evaluasi hasil program konseling

Konselor di SMP Kota Malang belum melaksanakan penilaian pengaruh program konseling. Hal ini akan berdampak pada biasnya tindak lanjut dari program konseling yang telah dilaksanakan. Dikatakan bias karena tidak ada data empiris ataupun rekaman data faktual yang memuat bagaimana perubahan tingkah laku konseli yang telah usai melaksanakan program konseling dengan konselor.

Konselor sekolah profesional sebagai bagian dari tim pendidik di sekolah memiliki kinerja melaksanakan program konseling yang menunjang pencapaian tujuan yang dicanangkan oleh sekolah (Dahir \& Stone, 2009). Kinerja konselor sekolah tersebut tertuang dalam program konseling dan program tersebut terbukti keefektifannya dalam pencapaian tujuan sekolah dan peningkatan prestasi belajar siswa (Astramovich, Coker \& Hoskins, 2005). Untuk menguji keefektifan dan memperbaiki program layanan bimbingan dan konseling perlu dilakukan eveluasi. Evaluasi yang dilakukan konselor mencakup penilaian segera, penilaian jangka pendek, dan penilaian jangka panjang. Evaluasi program layanan bimbingan konseling juga bisa menyediakan sumber informasi yang dibutuhkan untuk memverifikasi kekuatan program konseling (Otto, 2001).

(b) Pemanfaatan teknologi

Pemanfaatan teknologi dengan menggunakan media sosial untuk program konseling juga belum bisa dilaksanakan konselor di SMP Kota Malang tersebut. Salah satu faktor yang menjadi alasan konselor tidak melaksanakan konseling online adalah konselor belum memahami bagaimana merancang program tersebut. Dengan memanfaatkan media sosial seharusnya konselor mampu membuat sebuah konsep program konseling online. Upaya ini kemungkinan besar akan mendapat respon positif dari siswa untuk memanfaatkannya daripada penggunaan media kotak konseling sebagai media program konseling. Konseling online akan menjadi alternatif dalam pelaksanaan konseling. Hal tersebut diperkuat dengan pernyataan sebagaimana yang dikemukan oleh Mallen \& Vogel (2005: 764):

Any delivery of mental and behavioural health services, including but not limited to therapy, consultation, and psychoeducation, by a licensed practitioner to a client in a non-[face-to-face] setting through distance communication technologies such as the telephone, asynchronous e-mail, synchronous chat, and video conferencing.

Berdasarkan pernyatan di atas dapat dipahami bahwa program konseling online saat ini telah didukung dengan berbagai media dan diperkirakan meningkat dalam 10 tahun ke depan. Konseli dapat menggunakan video conference, synchronous chat, dan asynchronous e-mail dengan konselor profesional di samping konseling dengan format tatap muka. Kondisi tersebut mengharuskan konselor untuk mrmbuka mata terhadap perkembangan zaman dan menguasai mediamedia konseling online. Jika tidak kondisi program konseling di Indonesia kian terpuruk, konselor dipandang gagap teknologi, terlalu rigit dan tidak mau berkembang.

Berdasarkan pernyatan di atas dapat dipahami bahwa konseling online bukanlah proses yang sederhana. Sebaliknya, konseling online merupakan proses yang kompleks. Masalah etika, masalah teknologi, latar belakang pendidikan dan keterampilan adalah isu-isu utama dalam konseling online. Pemahaman konselor akan kompleksnya proses konseling online, perlu dirumuskan program yang jelas untuk mengimplementasikan konseling online yang efektif bagi siswa.

(c) Pembuatan agenda yang jelas

Konselor di SMP Kota Malang belum membuat agenda yang jelas dalam melaksanakan konseling. Konseling dilakukan secara insidental, yaitu jika memang terjadi permasalahan yang bisa dibantu dengan program konseling. Salah satu faktor yang menjadi alasan konselor tidak mengagendakan secara jelas program konseling adalah karena konselor menganggap bahwa kapan terjadinya masalah tidak bisa ditebak.

Jika merujuk pada teori, layanan bimbingan dan konseling di sekolah adalah bagian integral dari sistem pendidikan di sekolah (Gysbers, 2001) yang menangani perkembangan akademik, karir, dan kompetensi dan keterampilan pribadi/sosial setiap siswa (ASCA, 2012; Landers dkk., 2008). Salah satu karakteristik dari bimbingan dan konseling di sekolah adalah bimbingan dan konseling adalah sebuah program. Bimbingan dan konseling 
adalah sebuah program memiliki makna aktifitas bimbingan dan konseling seharusnya direncanakan dengan baik, terstruktur, dan diimplementasikan secara sistematis (Gysbers \& Henderson, 2006), termasuk pemrograman terhadap layanan konseling. Dari pernyataan tersebut dapat dipahami bahwa perencanaan program konseling adalah salah satu unsur yang sangat penting untuk memandu konselor mengimplementasikan program konseling. Kehati-hatian diperlukan dalam menyusun perencanaan program layanan (Gysbers \& Henderson, 2006). Ini dimaksudkan agar perencanaan program konseling dapat diterapkan dan dirasakan pengaruhnya oleh siswa. Dalam menyusun progam bimbingan dan konseling yang komprehensif, konselor perlu melakukan need assesment (Gysbers \& Henderson, 2006; Lau \& Fung, 2008).

\section{SIMPULAN DAN SARAN}

Berdasarkan hasil analisis data kuesioner evaluasi program konseling yang berperan sebagai instrumen utama dan didukung hasil analisis data pedoman wawancara dan studi dokumentasi program konseling didapatkan hasil bahwa program konseling di SMP Kota Malang masih jauh dari standar. Hal ini dikarenakan di SMP tersebut hanya $51,1 \%$ aspek kegiatan program konseling telah terlaksana dengan baik. Selanjutnya, di SMP tersebut setidaknya terdapat $17,8 \%$ aspek kegiatan program konseling yang hanya terlaksana sebagaian. Sedangkan untuk program konseling yang tidak terlaksana sama sekali di SMP tersebut adalah 31,1\%.

Temuan penelitian menunjukkan bahwa implementasi program konseling di SMP Kota Malang masih jauh di bawah standar. Hasil tersebut seyogyanya mendapatkan perhatian oleh sekolah terutama konselor sebagai pelaksana program konseling di sekolah. Konselor sebagai pelaksana program konseling hendaknya memperbaiki kualitas menjalankan program konseling yang sesuai dengan standar yang ditetapkan. Hal ini dilakukan agar tujuan program tersebut dapat tercapai dan memberikan pengaruh positif bagi siswa yang menjadi sasaran program tersebut. Selain itu, temuan penelitian ini juga dapat dijadikan masukan dalam rangka membenahi sistem pengawasan terhadap program bimbingan dan konseling khususnya program konseling di sekolah, yang dalam hal ini dapat dilakukan oleh kepala sekolah dan jajarannya.

\section{DAFTAR RUJUKAN}

Akhmadi, A. 2012. Peningkatan Kemampuan Konselor Profesional, Kajian Materi Diklat Jarak Jauh Guru Bimbingan Konseling. (Online), (www.himcyoo.files.wordpress.com), diakses 12 Februari 2014.

ASCA. 2012. The Professional School Counselor and Comprehensive School Counseling Programs. (Online), (www.schoolcounselor.org), diakses 4 Maret 2014.

Astramovich, R. L., Coker, J. K., \& Hoskins, W. J. 2005. Training school counselors in program evaluation. (Online), (professionalschoolcounseling.org), diakses 25 November 2015.

Astramovich, R. L., \& Coker, J. K. 2007. Program Evaluation: The Accountability Bridge Model for Counselors. Journal of Counseling \& Development, 85: 162-172.

Corey, G. 2009. Theory and Practice of Counseling and Psychotherapy. Belmont, CA: Thomson Brooks/Cole.

Dahir, C. A., \& Stone, C. B. 2009. School Counselor Accountability: The Path to Social Justice and Systemic Change. Journal of Counseling \& Development, 87: 12-20.

Dimmitt, C. 2010. Evaluation In School Counseling: Current Practices and Future Possibilities. Counseling 
Outcome Research and Evaluation, 1 (1): 44-56.

Fitzpatrick, J. L., Sanders, J. R., \& Worthen, B. R. 2004. Program Evaluation: Alternative Approaches and Practical Guidelines. Boston: Pearson.

Gibson, R. L. \& Mitchell, M. H. 2010. Bimbingan dan Konseling. Alih bahasa: Yudi Santoso. Yogyakarta: Pustaka Belajar.

González-Prendes, A. A., \& JozefowiczSimbeni, D. M. H. 2009. The Effects of Cognitive-Behavioral Therapy on Trait Anger and Paranoid Ideation. Research on Social Work Practice, 19 (6): 686-693.

Gysbers, C. N. \& Henderson, P. 2006. Developing \& Managing Your School Guidance and Counseling Program. American Counseling Association: Alexandria.

Gysbers, C. N. 2008. Individual Student Planning in the United States: Rationale, Practices, and Results. Asian Journal of Counselling, 15 (2): 117-139.

Gysbers, C. N., 2001. School Guidance and Counseling in the 21st Century: Remember the Past into the Future. Professional School Counseling, 5 (2): 1-16.

Gysbers, C. N., Stanley, J. B., KosteckBunch, L., Magnuson, C. S., \& Starr, M. F. 2008. Missouri Comprehensive Guidance Program: A Manual for Program Development, Implementation, Evaluation and Enhancement. Missouri: Missouri Center for Career Education.

Hansen, J. C., Stevic, R. R., \& Warner, R. W. 1977. Counseling: Theory and Process. USA: Allyn and Bacon, Inc.

Landers, P. A., Adorno, D., Aleman, N. M., Silano, M. M., \& Turek, W. 2008. Comprehensive School Counseling: A Guide to Comprehensive School Counseling Program Development. State of Connecticut.
Lau, P. S., Y. \& Fung, S. 2008. School Guidance and Counseling in an International Context: A Reaction Paper. Asian Journal of Counselling, 15 (2): 207-228.

Mallen, M. J., \& Vogel, D. L. 2005. Introduction to the Major Contribution: Counseling Psychology and Online Counseling. The Counseling Psychologist, 33 (6): 761 775 .

McKenna, C. 1981. Making Evaluation Manageable. Journal of Extention, 114.

Missouri Department of Elementary and Secondary Education. 2000. Guidelines for Performancebased Professional School Counselor Evaluation. Jefferson City, MO: Author.

Olubusayo, A. 2014. Effect of Cognitive Restructuring on the Reduction of Mathematics Anxiety among Senior Secondary School Students in Ogun State, Nigeria. International Journal of Education and Research, 2 (2): 120.

Otto, C. N. C. 2001. An Evaluation of the School Counseling Program at Stillwater Area Schools in Stillwater, Minnesota. University of WisconsinStout: The Graduate College.

Saputra, W. N. E. 2011. Meningkatkan Rasa Percaya Diri Siswa SMA dengan Konseling Kelompok Gestalt. Skripsi tidak diterbitkan. Surabaya: Universitas Negeri Surabaya.

Saputra, W. N. E. 2015. Perbandingan Prokrastinasi Akademik Siswa SMK melalui Penerapan Teknik Cognitive Restructuring dan Cognitive Defusion. Tesis tidak diterbitkan. Malang: Pascasarjana Universitas Negeri Malang.

Scheeringa, M. S., Salloum, A., Arnberger, R. A., Weems, C. F., AmayaJackson, L., \& Cohen, J. A. 2007. Feasibility and Effectiveness of 
Cognitive-Behavioral Therapy for Posttraumatic Stress Disorder in Preschool Children: Two Case Report. Journal of Traumatic Stress, $20(4)$ : 631-636.

Shertzer, B., \& Stone, S. C. 1980. Fundamental of Counseling. Boston: Houghton Mifflin Company.

Spilsbury, G. 2012. Solution-Focused Brief Therapy for Depression and Alcohol Dependence: A Case Study. Clinical Case Studies, 11 (4): 263-275.

Winkel, W. S. 1991. Bimbingan Konseling di Institusi Pendidikan. Jakarta: Grasiondo.

Yusuf, S., \& Nurihsan, J. 2009. Landasan Bimbingan \& Konseling. Bandung: Remaja Rosdakarya. 